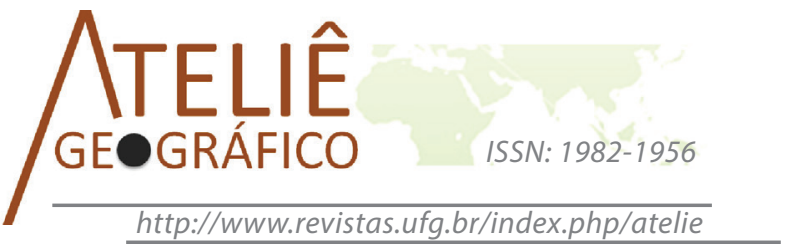

\section{Participação social em Unidades de Conservação: o caso do Parque Estadual da Ilha do Cardoso (São Paulo, Brasil)}

\author{
Social participation in Protected Areas: the case of the \\ "Ilha do Cardoso" State Park (São Paulo, Brazil)
}

\section{La participación social en Áreas Protegidas: el caso del Parque Estadual "Tha do Cardoso" (São Paulo, Brasil)}

\author{
Luciene Cristina Risso \\ UNESP / Ourinhos \\ luciene@ourinhos.unesp.br
}

\begin{abstract}
Resumo
A participação social nas áreas protegidas do Brasil está garantida pela Lei 9985/2000, que criou o Sistema Nacional de Unidades de Conservação. Assim, avaliar a participação social e a visão dos representantes comunitários concernente ao conselho consultivo do parque estadual da Ilha do Cardoso (litoral sul do Estado de São Paulo, Brasil) constituíram-se nos objetivos centrais desse trabalho. Para investigar essa questão, a metodologia constou de pesquisa bibliográfica sobre o tema e do parque em estudo; aplicação de dois questionários semiestruturados, organização e reflexão desse banco de dados, e, por fim, algumas proposições. Como resultados obtidos do questionário aplicado aos representantes comunitários do conselho consultivo do parque, estes reconheceram a importância e eficácia da instância participativa, principalmente na questão de serem ouvidos e quanto à regulamentação do uso do solo. Dessa maneira, os conselhos são instrumentos impares na gestão, substancialmente porque atenuam a problemática complexa entre parques e comunidades.

Palavras-chave: Áreas protegidas, conflitos, comunidades tradicionais, gestão participativa.
\end{abstract}

\footnotetext{
Abstract

The social participation in protected areas of Brazil is guaranteed by the Law $9985 / 2000$, which created the National System of Conservation Units. Thereby, to
} 
evaluate the social participation and the vision of the community representatives concerning the advisory board of the "Ilha do Cardoso" State Park (south coast of São Paulo, Brazil) was constituted the central objectives of this work. In order to investigate this question, the methodology consisted of a literature search on the theme and the park studied; application of two semi-structured questionnaires, organization and reflection of this database, and finally, some propositions. As the results obtained from questionnaire applied to the community representatives of the advisory board from the park, these recognized the importance and effectiveness of participative instance, mainly the matter of being heard and about the regulation of land use. In this way, the boards are odd instruments in the management, substantially because they attenuate the complex problematic between parks and communities.

Keywords: protected areas, conflicts, traditional communities, participative management.

\begin{abstract}
Resumen
La participación social en áreas protegidas de Brasil es garantizada por la Ley 9985/2000, que creó el Sistema Nacional de Unidades de Conservación. Se busca con este trabajo evaluar la participación social y la visión de representantes de la comunidad en relación al consejo del parque estadual "Ilha do Cardoso", ubicado en la costa sur del Estado de São Paulo, Brasil. Los procedimientos metodológicos se constituyeron en el levantamiento y lectura bibliográfica sobre el tema y el parque en estudio, aplicación de dos cuestionarios semiestructurados, sistematización y análisis de los datos primarios obtenidos y, por último, la sugerencia de algunas proposiciones. Los resultados obtenidos han permitido decir que los representantes de la comunidad del consejo del parque reconocen la importancia y la eficacia de la instancia de participación, especialmente el hecho de que han sido escuchados en cuanto a la regulación del uso del suelo. Por lo tanto, los consejos son instrumentos importantes de gestión, sobretodo porque disminuyen el problema complejo entre los parques y las comunidades.

Palabras clave: Áreas protegidas, conflictos, comunidades tradicionales, gestión participativa.
\end{abstract}

\title{
Introdução
}

No Brasil, as Unidades de Conservação foram criadas dentro do modelo americano de parques, ou seja, os parques deveriam ser áreas de preservação da natureza sem a presença humana, era o que Diegues (1994) chamou de mito moderno da natureza intocada. A consequência disso foi a criação de vários parques, onde viviam comunidades indígenas tradicionais e não tradicionais, sobressaindo o conflito dessas populações humanas quando perceberam que seus territórios estavam se transformando em áreas protegidas pelo Estado. Esse contexto de criação de parques sem participação social, de "cima para baixo", ocasionou expropriações, desapropriações e inúmeros conflitos socioambientais em territórios onde viviam comunidades indígenas e tradicionais. 
O caso do parque estadual da Ilha do Cardoso não é diferente de outros parques e reservas brasileiras ${ }^{1}$. Por quase todo o parque estadual da Serra do Mar, diversas populações caiçaras sofreram (e ainda sofrem) com essas transformações.

As populações que permaneceram nessas áreas (ou melhor, em seus lugares, seus territórios) para lutarem pelos seus direitos territoriais, foram proibidas de desenvolver atividades tradicionais diretas (como agricultura, caça, coleta etc.), gerando mais conflitos e incompatibilidades com a legislação vigente relativa aos parques e reservas.

Os anos se passaram, e as populações que permaneceram em seus territórios tiveram que, forçosamente, adaptar-se às restrições e (re) criar novas formas econômicas, sociais e culturais para viverem nessas áreas protegidas. Portanto, os conflitos territoriais são inerentes, e cada parque lida de modo singular com essa situação. Assim, o esforço da gestão para uma efetiva participação social e minimização de conflitos é fundamental nos dias atuais, e os conselhos são instrumentos essenciais nesse processo.

A escolha da área de estudo, o parque estadual da Ilha do Cardoso, guarda relação com a eficácia de gestão (82,68\% segundo Faria, 2014), que é considerada uma referência nesse âmbito, com comunidades muito envolvidas na gestão participativa. Esse cenário instigou a pesquisa que teve como objetivo principal avaliar a participação social no parque estadual da Ilha do Cardoso (PEIC) e a visão dos representantes comunitários sobre o papel do conselho. $\mathrm{O}$ artigo envolveu a discussão da participação, unidades de conservação e comunidades.

\section{Metodologia}

A metodologia constou de revisões bibliográficas, trabalhos de campo, organização e reflexão dos dados levantados e, por fim, algumas proposições.

Foram aplicados dois questionários. O primeiro para o segmento civil, entregue aos conselheiros e convidados membros das comunidades tradicionais caiçaras do parque estadual da Ilha do Cardoso (PEIC) e um questionário para a atual gestora. Mesmo que a gestora seja presidente do conselho, os diferentes questionários foram distintos, uma vez que se objetivava avaliar a visão específica dos representantes comunitários.

Os questionários foram aplicados em cinco de novembro de 2013, durante a reunião do conselho. Outros campos foram necessários na área de estudo, para coleta e análise de atas e outras informações e observações.

Para avaliar a participação foram utilizados alguns indicadores de acordo com Loureiro (2008, p.249-250):

[...] Participação - aqui se deve pensar em avaliar: 1) capacidade de todos os envolvidos em tomar decisões (o que envolve condições de estar presente, tipo de linguagem utilizada nas reuniões e acesso a informações estratégicas

1. Vide outras pesquisas da autora (RISSO, 1998; RISSO, 2001). Ambas no parque estadual da Serra do MarNúcleo Picinguaba- Ubatuba-SP. 
para a tomada de posição); 2) quantidade e representatividade das associações na gestão da UC; 3) atuação por associações e/ou indivíduos nas atividades e nas reuniões promovidas na UC, sejam estas as reuniões ordinárias ou extraordinárias do conselho, encontros promovidos por um grupo de trabalho ou câmara técnica do conselho, ou ainda qualquer outra atividade aberta e de interesse para a gestão da Unidade; e 4) existência de um contexto de livreassociação que favoreça a organização e a atuação coletiva das populações.

Além disso, a discussão sobre democracia representativa e democracia participativa, contextualização de comunidades tradicionais em áreas protegidas de proteção integral, contribuíram muito para o debate e para algumas proposições.

\section{Participação social e democracia}

A participação social é condicionada historicamente. No Brasil, passou a ser reivindicada desde a década de 1960, "quando Paulo Freire cunhou a expressão "cultura do silêncio' para designar a secular exclusão política da maioria do povo brasileiro" (STRECK; ADAMS, 2006, p.96).

Para Santos; Avritzer (2005, p.55) "a reinvenção da democracia participativa nos países do sul está intimamente ligada aos recentes processos de democratização pelos quais passaram esses países". O autor cita, ainda, o caso brasileiro, ao qual diz que o país alternou "períodos autoritários e períodos democráticos até 1985".

As lutas sociais pela democracia cresceram perante a repressão na ditadura militar, "cujas conquistas, em nosso país, foram ao menos parcialmente incorporadas na Constituição Federal de 1988" (STRECK; ADAMS, 2006, p.96). Dessa forma, a "onda" democrática se deu nos anos de 1980 e 1990 (SANTOS; AVRITZER, 2005, p.55).

A Constituição Federal previu, em seu artigo 1, parágrafo único, que "todo poder emana do povo, que o exerce indiretamente, através de seus representantes eleitos, ou diretamente, nos termos desta Constituição". A participação, portanto, é um princípio inerente à democracia. Outros artigos da Constituição de 1988 preveem a participação do cidadão na gestão pública, através de política da descentralização pública (BRASIL, 1988, artigo 198, III, artigo 194, VII, Artigo 187, caput, artigo 204, 22).

Assim, a participação social tomou força no início dos anos 1990, "no bojo desse processo de reforma da administração pública na América Latina" (MILANI, 2008, p. 553) e, atualmente, tornou-se um dos princípios norteadores na gestão de políticas públicas.

Durante o processo de redemocratização do Brasil, a luta pelos direitos a bens públicos e participação em decisões locais são alguns exemplos dessa pulsão participativa.

O termo participação social pode ser entendido como "um processo que gera a interação entre diferentes atores sociais na definição do espaço comum e do destino coletivo" (LOUREIRO, 2004, p.44). Para Milani (2008, p.560) a participação social cidadã é "aquela que configura formas de intervenção individual e coletiva, que supõem 
redes de interação variadas e complexas determinadas (...) por relações entre pessoas, grupos e instituições com o Estado".

Na contemporaneidade, a participação social nos espaços públicos pressupõe democracia e construção/aprendizagem da cidadania. Mas, só participar dá sentido à democracia?

Concernente à temática, Santos e Avritzer (2005, p.72) afirma que "a democracia tem um valor intrínseco e não uma mera utilidade instrumental". Para entender esse pensamento, recorre-se ao debate histórico sobre as visões de democracia na Europa. Para o autor supracitado há quatro fases de debates sobre o tema. O primeiro debate iniciou-se no século XIX, com a luta pela democracia como forma de governo. O segundo aconteceu pós-segunda guerra mundial, quando o foco direcionou-se às condições estruturais da democracia.

O terceiro debate radica na forma da democracia. Há duas formas de democracia: a democracia representativa e a democracia participativa. Contudo, nesse debate, a democracia representativa é supervalorizada.

Funda-se, portanto, uma concepção hegemônica, segundo a qual praticamente se abandona a mobilização social na Europa, prevalecendo a valorização do papel dos mecanismos de representação. Para Shumpter (1942:269, apud SANTOS; AVRITZER, 2005, p.41-42): “o cidadão comum não tinha capacidade ou interesse político senão para escolher os líderes aos quais caberia tomar as decisões". E, contrapondo-se a essa concepção, surge o quarto debate, referente à qualidade da democracia e novas concepções não hegemônicas.

Ainda sobre essa visão hegemônica, o autor aponta para o fato de que a mesma foi estendida para os demais países, e propõe uma reconstrução do debate:

[...] a forma hegemônica da democracia, a democracia representativa elitista, propõe estender ao resto do mundo o modelo de democracia liberal-representativa vigente nas sociedades do hemisfério norte, ignorando as experiências e as discussões oriundas dos países do Sul no debate sobre a democracia. A partir de uma reconstrução do debate sobre a democracia da segunda metade do século $\mathrm{XX}$, pretendemos propor um itinerário contra-hegemônico para o debate sobre a democracia, resgatando aquilo que ficou nas entrelinhas desse debate nesse período (SANTOS; AVRITZER, 2005, p. 43).

No entanto, a concepção da democracia representativa não está conseguindo explicar o paradoxo da qualidade da participação. Sobre isso, diz Santos; Avritzer (2005, p.42):

[...] Quanto mais se insiste na fórmula clássica de democracia de baixa intensidade, menos se consegue explicar o paradoxo de a extensão da democracia ter trazido consigo uma enorme degradação das práticas democráticas. Aliás, a expansão global da democracia liberal coincidiu com uma grave crise desta nos países centrais onde mais se tinha consolidado, uma crise que ficou conhecida como a da dupla patologia: a patologia da participação, sobretudo em vista do 
aumento dramático do abstencionismo; e a patologia da representação, o fato de os cidadãos se considerarem cada vez menos representados por aqueles que elegeram. Ao mesmo tempo, o fim da guerra fria e a intensificação dos processos de globalização implicaram uma reavaliação do problema da homogeneidade da prática democrática.

Essa citação contribui, sobremaneira, para explicar a marcante vulnerabilidade na participação democrática.

É o caso do estudo de Guizardi e Pinheiro (2006) acerca dos conselhos na área da saúde, no qual concluíram que diversos problemas estavam comprometendo a efetiva participação social: desigualdade no saber formal, ou seja, os conselheiros que não sabiam de termos técnicos eram conduzidos na reunião e havia pouco espaço para debaterem as reivindicações de suas comunidades; problemas de deslocamento; disponibilidade de tempo e assessoria institucional.

Outros problemas detectados por Milani (2008) relacionam-se com as desigualdades existentes na participação; quem participa e como se dá o processo de construção do interesse coletivo. Além disso, está-se vivendo "a crise da democracia representativa, tanto em termos de confiança dos cidadãos nas instituições políticas quanto à capacidade das administrações públicas" (MILANI, 2008, p.555).

Loureiro (2008, p.244) também advoga que só a democracia representativa não é o suficiente e afirma que "a mobilização social e os tipos de representação devem buscar um novo modo de relacionar Estado e sociedade civil, para que haja um novo modo de governar com a presença de agentes não estatais nos órgãos públicos”.

Milani (2008) chama a atenção para o fato de que, como a participação deriva de uma concepção de cidadania ativa, a cidadania define os que pertencem (inclusão) e os que não; "logo, a participação se desenvolve em esferas sempre marcadas também por relações de conflitos ${ }^{1}$ e pode comportar manipulação” (MILANI, 2008, p.560).

Nessa direção, Strech e Adams (2006, p.96) destacam a “(...) tendência de a participação ser sugada no labirinto dos canais de participação que não se comunicam e nos quais muitas vezes não se vê a saída em termos de resultados".

A participação foi uma conquista histórica, mas como seu discurso atual é atraente, alerta-se para que o mesmo não sirva de instrumento de manipulação e "meros instrumentos de convalidação social" (RODRIGUES, 2001).

As vulnerabilidades participativas acontecem porque "são fortemente contestadas pelas elites excludentes frontalmente ou descaracterizados por via da cooptação ou da integração" (SANTOS; AVRITZER, 2005, p.60) e ainda pela burocratização da participação e clientelismo. Além disso, o debate fica mais agudo "naqueles países nos quais existe maior diversidade étnica (...)” (SANTOS; AVRITZER, 2005, p.50).

Em contraposição a esse debate tradicional, a democracia participativa, ou então, as formas de combinação entre democracia representativa e participativa, propõe 
formas interessantes e com grande potencial, chamadas por Santos e Avritzer (2005, p.75) de "formas de coexistência e complementaridade".

O debate não hegemônico entende a democracia participativa como "um dos cinco campos sociais e políticos nos quais, no início do novo século, está sendo reinventada a emancipação social" (SANTOS; AVRITZER, 2005, p.55). Castoriadis (1986) chama de novo eidos, ou seja, uma nova política baseada na criatividade dos atores sociais. Santos; Avritzer (2005, p.51) reconhece essa democracia como a pluralidade humana, gramática social e cultural e aconselha que as aspirações democráticas devam recusar caricaturas da democracia.

Por fim, acredita-se que se deve fortalecer a democracia participativa, num debate amplo e plural, considerando a criatividade cultural.

\section{Unidades de Conservação: espaços de participação?}

No Brasil, as unidades de conservação foram criadas principalmente na década de 1970, num contexto não participativo, sem consulta pública, dentro do modelo americano de parques, em territórios onde já viviam comunidades tradicionais e indígenas.

As comunidades e administradores (diretores) tiveram que conviver com os inúmeros conflitos relacionados com a situação fundiária e com a incompatibilidade do modo de vida tradicional com as novas restrições ambientais impostas. Houve proibições de desenvolverem atividades diretas (como agricultura, caça, coleta etc.), gerando antagonismos com os objetivos previstos nas leis (DIEGUES, 1994; RISSO, 1998; RISSO, 2001; AMEND; AMEND, 1992; CLAY, 1985; GOMEZ-POMPA; KAUS, 1992).

Essa política culminou em abandonos, expulsões, expropriações da área e migrações para bairros urbanos e rurais próximos. Em geral, o direito à permanência dos moradores foi garantido pela resistência e luta. Muitas ONGS, professores universitários (um deles foi o Prof. Dr. Antonio Carlos Diegues) e técnicos ajudaram as populações nessa luta, via esferas do poder público (promotoria pública) e em planos de gestão da própria unidade de conservação. Nos planos de gestão, houve a discussão de quem permanecia ou não na unidade, levando ao debate de comunidades tradicionais $\mathrm{X}$ não tradicionais. As tradicionais teriam o direito de permanecer, desde que respeitassem as normas.

A esperança dos movimentos sociais ou daqueles que defendiam as comunidades tradicionais era que o projeto de Lei 2892/1992 resolvesse a questão da sobreposição das áreas decretadas onde viviam as comunidades. No entanto, após a aprovação do projeto através da lei 9985/2000, que criou o SNUC - Sistema Nacional de Unidades de Conservação - foram vetados vários artigos que tratavam dessas questões ${ }^{2}$ e não houve

2. O primeiro veto foi em relação ao conceito de população tradicional e o segundo veto minou a possibilidade de conversão de categoria de uma UC de proteção integral para de uso sustentável, diante da presença de população tradicional (JUNQUEIRA E FERREIRA, 2012). 
uma mudança legal dentro da realidade tropical para permitir a presença de comunidades em unidades de proteção integral.

Pelo contrário, o sistema nacional de unidades de conservação continuou dentro de uma visão preservacionista e não acompanhou a ideia evolutiva do conceito de parques (inserindo populações) como sugeriram os principais órgãos de conservação internacional como a IUCN (União Internacional para a conservação da Natureza).

Atualmente, as comunidades humanas do interior do parque estadual ainda convivem com as restrições, as quais atingem diretamente a reprodução social e cultural, ou seja, não se pode construir casas novas, e reformas e pequenas construções devem obter autorização do Estado.

E nesse cenário, como essa população vai manter sua tradicionalidade? Como irá sobreviver? Essa reflexão vai de encontro com Alvaides (2013, p.123) que expressou igualmente essa preocupação: "Resta-nos o incômodo: como essa comunidade e cultura vai sobreviver, se seus filhos são impedidos de fazer do local o seu lar?”.

O modo de vida tradicional, com seus saberes e territorialidades diferenciadas em unidades de conservação integral, podem estar comprometidos sim, uma vez que para o pensamento preservacionista "a aversão a essas restrições impostas pode persuadir os residentes dos parques a ir viver em outros lugares, se as oportunidades assim o permitirem" (TERBORGH; PERES, 2002, p.341).

A intenção realmente é que as pessoas sejam retiradas de áreas protegidas. Para esse pensamento “[...] pessoas de todos os tipos, sejam indígenas ou não, representam uma ameaça séria à biodiversidade de qualquer parque, quando seus meios de vida são derivados dos recursos da área protegida" (TERBORGH; PERES, 2002, p.334), e a meta final é que os parques sejam "livres de pessoas" (p.337). Para isto, o autor apresenta estratégias e políticas para realocação:

[...] O problema de pessoas nos parques não admite a longo prazo outra solução satisfatória do que reduzir a pressão demográfica. O único meio completamente indolor de faze-lo é introduzir programas de planejamento familiar. Outras políticas mais assertivas incluem a imposição de restrições que desencorajem a continuidade da residência e ofereçam incentivos para sua relocação. Os piores cenários podem exigir medidas mais drásticas tais como negociar acordos ou criar encraves humanos, esperançosamente uma solução provisória (TERBORGH; PERES, 2002. p.345).

Esses incentivos de realocação são chamados de "empurrão puxão", ou seja, trata-se de pressões sociais que os administradores podem aproveitar para obter um reassentamento voluntário:

[...] O puxão pode ser criado de muitas maneiras: construção de escolas fora dos parques; disponibilização de titulação legal de terras, fornecimento de cuidados de saúde, oferecimento de programas de treinamento (TERBORGH; PERES, 2002, p.340). 
Há sérias controvérsias relativas a esse tipo de incentivo, porque há inúmeras pesquisas que mostram a eficácia da gestão de áreas conservadas por comunidades, como é o caso brasileiro das reservas extrativistas. E preocupa essa visão no caso brasileiro, em que os parques e outras categorias foram decretados sobre territórios ocupados há séculos, com modo de vida compatível com o uso dos recursos naturais. Se a biodiversidade deve ser preservada, as culturas - caiçara, indígena, quilombola - também são tão importantes quanto. Realocar populações significa acabar com os laços topofílicos, com a identidade, com os saberes tradicionais.

Essas questões delicadas permeiam a discussão da participação social na gestão das unidades, que mesmo obducta, emana nas reuniões do conselho consultivo.

Os conselhos consultivos são instrumentos de participação social em Unidades de Conservação. Eles foram criados pela obrigatoriedade do SNUC (artigo 29 da lei $9985 / 2000^{3}$ ), formalizando, assim, a instância da gestão participativa. De acordo com Streck e Adams (2006, p.111) o conselho consultivo é:

[...] uma forma híbrida de participação, situando-se, por um lado, no contexto das instituições oficiais e, por outro, mantendo a possibilidade de forte vinculação com as bases da sociedade que representam em determinado tema ou segmento social.

Sobre a composição dos conselhos, o artigo 17 do Decreto 4340 (BRASIL, 2002) diz que os conselhos serão presididos pelo chefe da unidade de conservação, o qual designará os demais conselheiros indicados pelos setores a serem representados e estabelece as competências do mesmo no artigo 20.

Dessa forma, os conselhos devem envolver as comunidades afetadas. Muitas delas, tradicionais, detentoras de saberes tradicionais do território ${ }^{4}$, mas muito afetadas com a constituição da área protegida. As reuniões dos conselhos consultivos tornaramse importantes espaços de discussão, diálogo e minimização de conflitos. No entanto, tem-se que levar em consideração a complexidade da questão de comunidades e áreas protegidas (proteção integral) e o respeito aos saberes tradicionais e ao modo de vida singular dessas comunidades.

\section{Participação social no parque estadual da Ilha do Cardoso - Cananéia/SP}

O Parque Estadual da Ilha do Cardoso (PEIC) está localizado no município de Cananéia, litoral sul do Estado de São Paulo (Figura 1). O parque foi criado através do Decreto $\mathrm{n}^{\circ} 40.319 / 1962$, apresentando cerca de 22.500 hectares, como forma de proteger a biodiversidade e suas belezas naturais, bem como conter a especulação imobiliária,

3. Cada unidade de conservação do grupo de Proteção Integral disporá de um Conselho Consultivo, presidido pelo órgão responsável por sua administração e constituído por representantes de órgãos públicos, de organizações da sociedade civil [...]

4. Há muitos estudos sobre a relação desses conhecimentos sobre a Natureza - Diegues (1994), Cunha e Almeida (2002), Posey (1995) entre outros. 
empresas extrativistas etc. Inclusive, um loteamento de luxo que estava sendo construído no Marujá foi desativado (RODRIGUES, 2001 p.59). O pedido de criação ocorreu do professor Paulo Duarte para a transformação do território da Ilha do Cardoso em área protegida (MENDONCA, 2000).

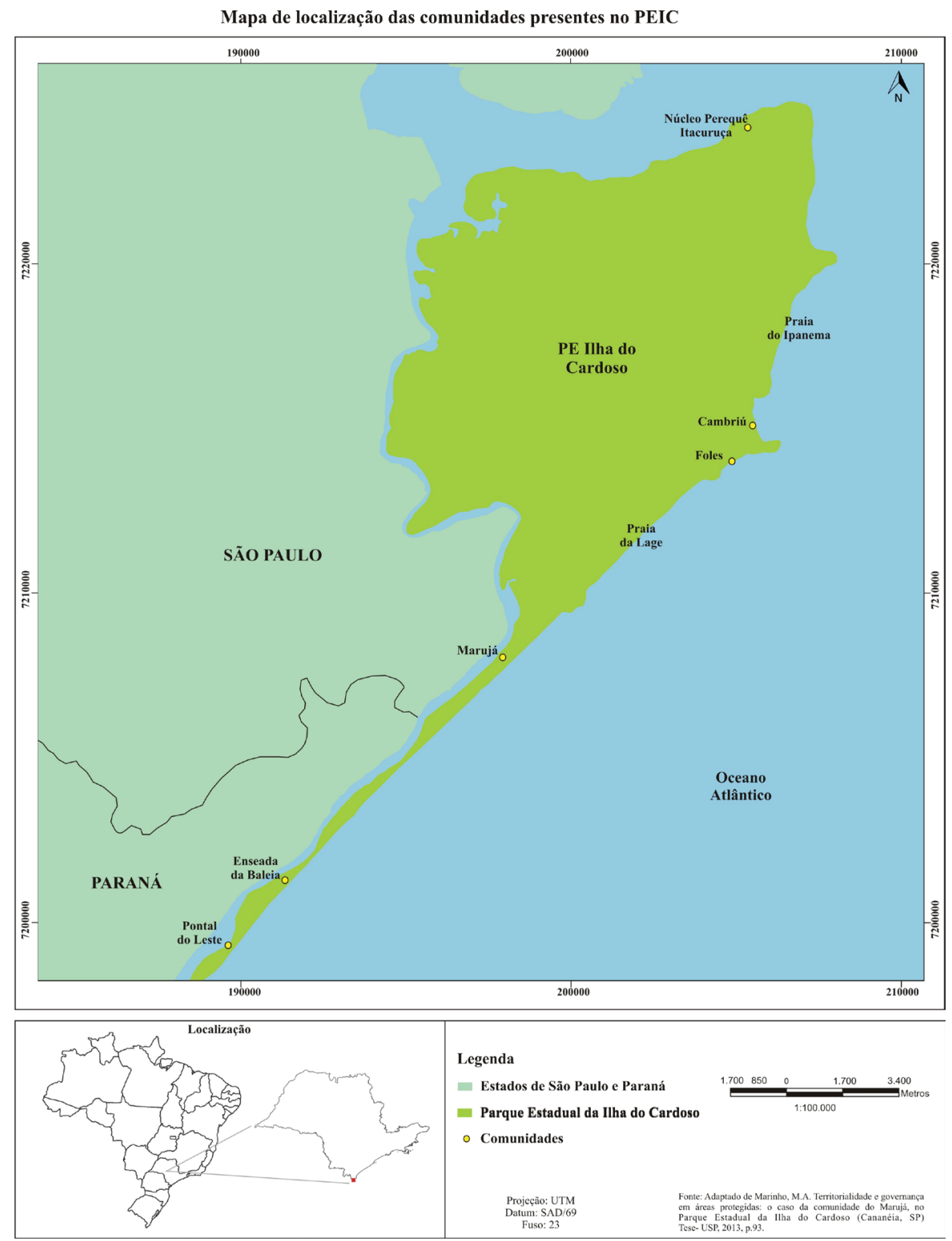

Figura 1. Mapa de localização das comunidades do parque estadual da ilha do Cardoso. Redesenhado por Angela Crespo. 
A transformação da área em parque trouxe diversos impactos. Um viés positivo vincula-se à conservação das paisagens naturais, da biodiversidade, e, também, à contribuição, mesmo que indireta, para que as comunidades não sofressem com a especulação imobiliária posteriormente.

O impacto negativo remete ao modelo de parques criado no Brasil, copiado do modelo americano, excludente, ou seja, um modelo preservacionista cujo eixo norteador define a retirada das comunidades humanas do seu interior.

No caso do PEIC, o processo realizou-se de "cima para baixo", sem considerar as comunidades já estabelecidas no local, trazendo diversos conflitos fundiários e territoriais diante das normas restritivas acerca de uma área de proteção integral, para a qual se recomenda o uso indireto dos recursos naturais.

Imagine-se tal cenário para os moradores. Sem consulta, sem participação, tiveram seus territórios transformados em áreas do Estado da noite para o dia. Seriam expulsos? Era o que muitos se perguntavam.

Iniciavam-se os impasses sobre a situação fundiária dos moradores, pois a maior parte deles não possuía título das terras, mas estavam nessa área antes do Decreto, portanto com direitos às terras. Outro impasse vincula-se à questão das terras de União e terras do Estado. Isso, de qualquer forma, foi positivo, pois retardou as ações discriminatórias do Estado.

Em 1974, foi instituído o primeiro plano de manejo do PEIC, numa visão preservacionista. Segundo Alvaides (2013, p.60), que analisou esse plano de manejo, "os moradores são acusados de se apossarem do território desde os tempos coloniais. Podemos nos indagar se os moradores se apossaram do território da Ilha do Cardoso ou se o Estado se apossou do território dos moradores". As consequências, portanto, foram expropriações e migrações para os bairros de Cananéia (GADELHA, 2008). Os que permaneceram, todavia, deveriam seguir as normas do parque, convivendo com as restrições e buscando novos caminhos.

A permanência dos moradores foi recomendada via portaria ministerial (número 139/1994), no momento da cessão da ilha da União para o Estado. Em 1995, o CONSEMA recomendou a inserção dos moradores no plano. Outro fato importante foi a adoção do processo participativo no início da elaboração da revisão do plano de manejo, em 1997, concluído em $2001^{5}$.

Em 1998, foi criado o comitê de apoio à gestão do parque ou conselho consultivo, "com a finalidade de subsidiar a direção do parque na tomada de decisões e encaminhamentos" (CAMPOLIM; PARADA; YAMAOKA, 2008, p.40), bem como para a revisão do plano de manejo (utilização do método ZOPP para participação social).

5. Esses planos de manejo foram financiados (grande parte) pelo Projeto de Preservação da Mata Atlântica (PPMA-governo alemão) via parceria, em 1996, com a Secretaria de Meio Ambiente do Estado de São Paulo. A obrigatoriedade da participação via conselhos só aconteceu mais tarde (2000). 
Esse fato foi inédito, pois foi posto em prática muito antes da obrigatoriedade brasileira do SNUC, em 2000.

Destaca-se que, a partir desse momento, o papel do gestor como intermediador foi fundamental, uma vez que ele, realmente, junto com esse conselho, legitimou a participação. Esse diretor fundou o comitê e permaneceu até 2007. Segundo Alvaides (2013) "com a saída dele o comitê ficou abalado e foi recompor-se em 2008, quando um novo gestor assumiu”. Este permaneceu até 2011 e uma nova gestora assumiu.

A atual gestora, Márcia Lima, assumiu em 2012, e as reuniões acontecem bimensalmente e têm muita participação das comunidades caiçaras, que estão distribuídas nas comunidades de Itacuruçá, Marujá, Enseada da Baleia, Pontal do Leste, Foles e Camboriú (vide, novamente, a Figura 1). Elas vivem hoje, basicamente, da pesca e do turismo. Contudo, várias atividades (como roçados, reformas de casas, entre outras) precisam de autorização do parque. Estão presentes também os índios guaranis Mbya, que "instalaram-se no parque no final de 1992, praticam a roça de subsistência e têm no artesanato a sua fonte de renda" (SÃO PAULO, 1998). Com uma associação de moradores caiçaras forte, as lideranças estão muito empenhadas na gestão participativa do parque e representam suas comunidades no conselho gestor do parque.

\section{Resultados}

O conselho, na gestão de 2012 a maio de $2014^{6}$, estava composto por dezoito (18) entidades. Dessas, sete do poder público e onze da sociedade civil. São elas: pela diretora do parque, prefeitura municipal de Cananéia, Colônia dos pescadores de Cananéia, Associação comercial de Cananéia, Secretaria da Educação, Polícia Ambiental, ONG IPEC, Rede Cananéia, Câmara Municipal, ICMBIO, Instituto Florestal, comunidades tradicionais de Pontal do Leste, Itacurucá (AMOIP-Associação de Moradores de Itacuruçá e Pereirinha), Marujá (AMOMAR-Associação de Moradores do Marujá), Enseada da baleia, Cambriú, Foles e Vila Rápida.

Referente à aplicação dos questionários sobre o papel dos conselhos em parques, a amostra limitou-se aos conselheiros e convidados. Das dezoito entidades integrantes da composição do conselho consultivo, foram coletados dados de cinco entidades $(27,77 \%$ do total), uma do poder público e quatro da sociedade civil. Do poder público, somente os dados da presidente do conselho - a gestora do parque - foram obtidos.

Das quatro entidades da sociedade civil, duas entidades eram representantes das comunidades caiçaras da região: 1) Associação das comunidades de Itacuruçá e Pereirinha - AMOMAR (3 pessoas - titular, suplente e um convidado) e 2) Associação de Moradores do Marujá - AMOIP (3 pessoas - titular, suplente e convidado) e duas entidades eram da ONG Rede Cananéia (1 pessoa) e Colônia dos pescadores de Cananéia Z-9 (1 pessoa), num total de nove pessoas entrevistadas. Portanto, a organização contou com os dados de 8 conselheiros, mais a entrevista da gestora do PEIC.

6. Após essa data iniciou-se um novo conselho. 
A maior parte dos entrevistados é representante das comunidades da Ilha do Cardoso, que sofreram diretamente com a criação do parque na década de 1960. São lideranças chaves no processo de gestão participativa. Portanto, os resultados acabaram expressando a opinião das comunidades envolvidas.

Sobre o perfil dos entrevistados, 5 eram do sexo masculino e três do sexo feminino. A faixa etária da maioria variava de 30 a 40 anos (Figura 2) e a taxa de escolaridade incidia no ensino médio.

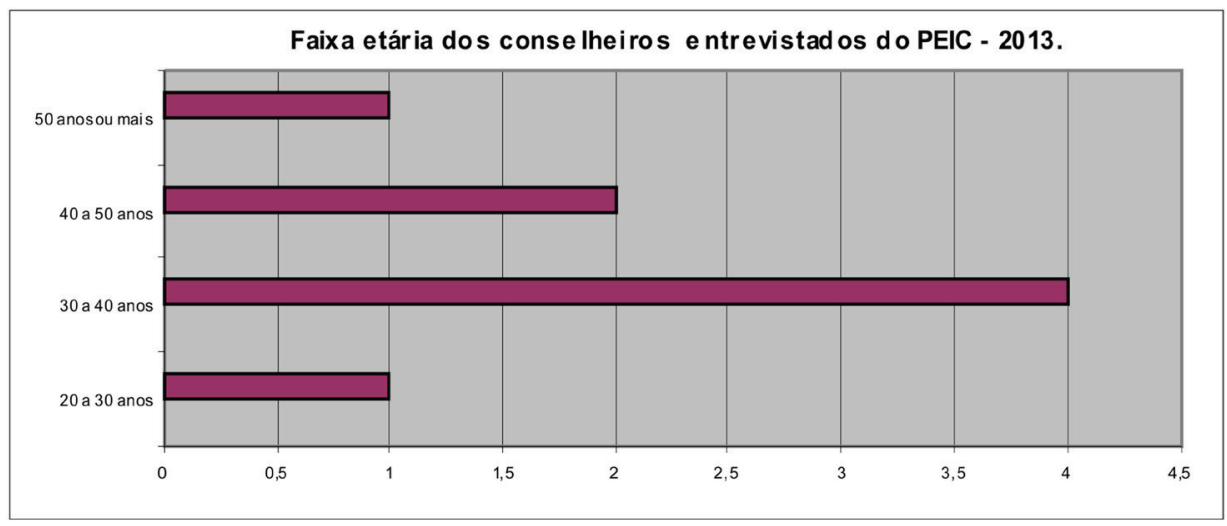

Figura 2. Faixa etária dos conselheiros entrevistados do PEIC (Parque

Estadual da Ilha do Cardoso), 2013.

Fonte: pesquisa direta.

A maioria é nascida e residente na praia do Pereirinha/praia da lage e na praia do Marujá, ambas situadas na Ilha do Cardoso.

Há diversificação quanto à profissão dos entrevistados (Figura 3). Sobre isso, historicamente as comunidades caiçaras eram consideradas essencialmente como lavradoras-pescadoras, ou seja, elas garantiam "(...) a maior parte de sua subsistência com a produção de roça, complementada pela pesca (ou pela caça) como fonte de proteína" (ADAMS, p.134). Com a desorganização agrícola, a pesca tornou-se a atividade principal passando a serem designados como pescadores artesanais (RISSO, 2001).

Atualmente, a atividade pesqueira é impar, mas complementada por outras atividades, como monitorias ambientais e turismo (Figura 3). A agricultura, no caso dos parques, também diminuiu na área por causa do regulamento dos parques que proibiu o sistema itinerante. A roça, elemento importante da cultura caiçara, está restrita, hoje, em áreas menores e todos os roçados devem ser autorizados pelo parque. Essa autorização está fundamentada no artigo 42 §o (BRASIL, 2000 - Lei 9985/2000), o qual diz:

[...] até que seja possível efetuar o reassentamento de que trata este artigo, serão estabelecidas normas e ações específicas destinadas a compatibilizar a presença das populações tradicionais residentes com os objetivos da unidade, 
sem prejuízo dos modos de vida, das fontes de subsistência e dos locais de moradia destas populações, assegurando-se a sua participação na elaboração das referidas normas e ações.

Dessa forma, o momento da autorização desses roçados e reformas de casas são muito esperados durante as reuniões.

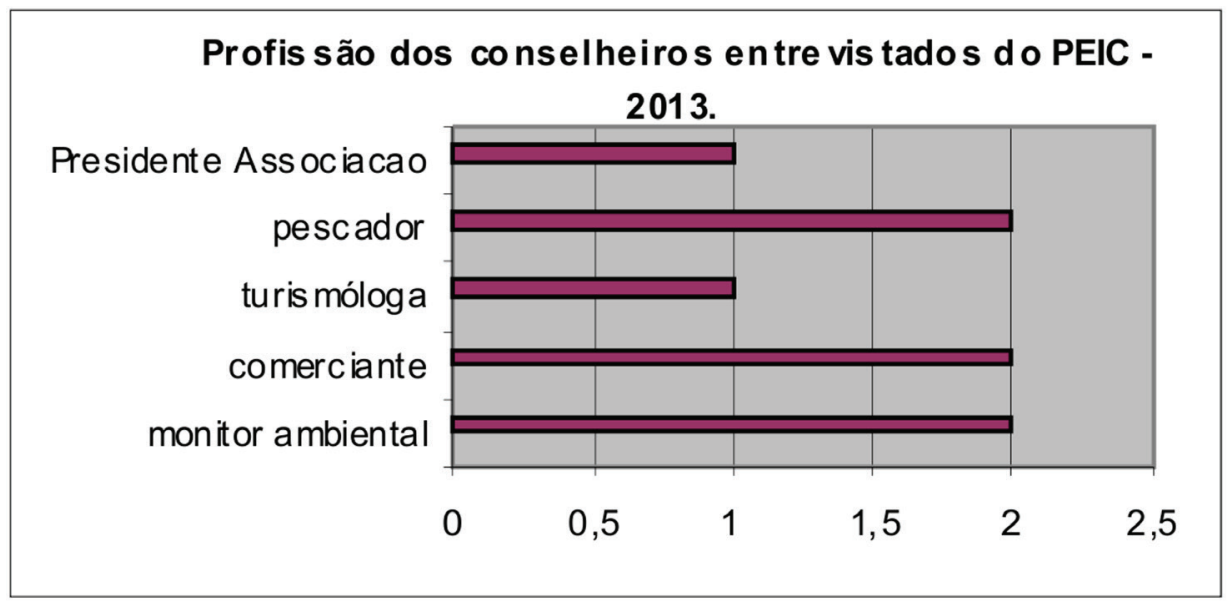

Figura 3. Profissão dos conselheiros do PEIC, 2013.

Fonte: pesquisa direta.

Quanto ao tempo de participação nos conselhos, a maior parte participa há mais de dez anos. Os motivos da entrada para a participação no conselho consultivo relacionaram-se, principalmente, com a questão do entendimento/interação dos assuntos e condições viáveis e melhores para os moradores.

Uma resposta singular foi "porque somos aliados do Estado. Pretendemos sempre ajudar". Essa declaração chamou a atenção porque entende que a gestão de uma unidade de conservação deve ser de forma participativa, numa parceria entre as comunidades e o parque. Significa, também, uma absorção da proposta de conservação da área.

Todos disseram que gostam de participar. Já o motivo disso, foi principalmente porque é uma forma de se inteirarem dos assuntos e defenderem seus direitos, como fica claro no depoimento desse entrevistado "para estar interado (sic) dos acontecimentos e defender interesses comunitários".

Foi unânime a afirmação de que os conselhos são efetivos e importantes. A efetividade foi percebida pelos entrevistados pelo próprio fator-participação (direito a voto, cadeira no conselho etc), e pela relativa resolução de problemas. 
E, são importantes para resolverem e debaterem conflitos que influenciarão na vida dos comunitários, como sintetizam os depoimentos: "é através dele que a comunidade sabe o que se passa em sua comunidade e entorno" e "porque é muito conflito nas comunidades". Quanto aos problemas enfrentados para participação no conselho, a maioria respondeu sobre a questão da distância (Figura 4):

\section{Principais problemas para a participação PEIC 2013}

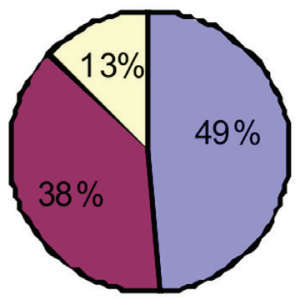

口distân cia Doutras ロnão

Figura 4. Principais problemas para a participação segundo os conselheiros entrevistados do PEIC, 2013.

Fonte: pesquisa direta.

Além do problema da distância, apresentado na Figura 4, a questão referente aos problemas comunitários e demora nos encaminhamentos revelaram um assunto chave e latente dos conflitos - as restrições de se viver em uma área protegida, como mostram os depoimentos a seguir:

"os problemas para as construções de casas tradicionais"

"acho que todos sabem que quase tudo depende também do Estado, algumas demandas demoram para serem liberadas, mas eu acho o conselho ótimo",

"ansiedade pelo encaminhamento, mediação de conflitos, ausência do poder público, participação, divisão de responsabilidades, nem todas as comunidades participam",

Quanto às propostas de melhorias, a proposta das reuniões itinerantes apareceu novamente como item fundamental de mudança (Figura 5), como forma de resolver o maior problema para a participação que era a questão da distância (Figura 4).

$\mathrm{O}$ outro ponto citado como proposta de melhoria liga-se à questão da agilidade das melhorias, que tem relação com a demora no trâmite dos requerimentos solicitados pelos comunitários durante as reuniões. 


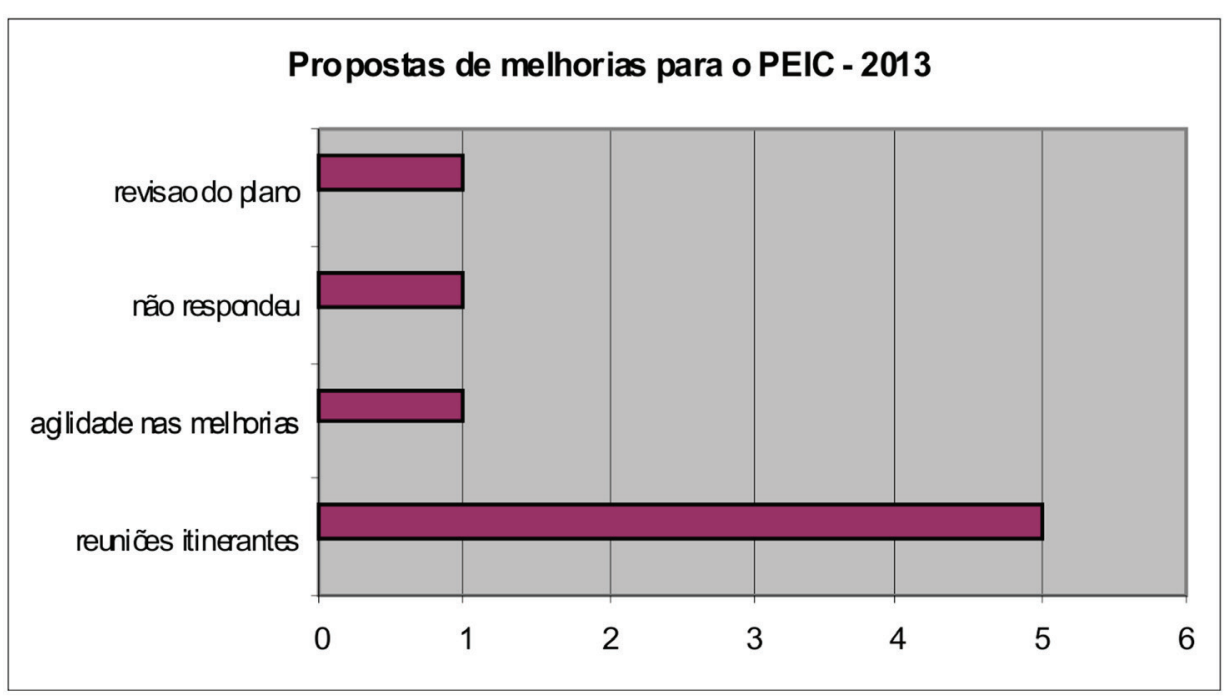

Figura 5. Propostas de melhorias

Fonte: pesquisa direta realizada em 2013

O conselho consulta, não delibera, mas a opinião dos membros é muito considerada pelo parque e depois pelo Instituto Florestal e Fundação Florestal. São nesses momentos que se percebem os conflitos inerentes ao processo. As petições são autorizações para roçados, reformas, assuntos de pesca e turismo, e assuntos mais polêmicos sobre demolições de edificações de moradores não tradicionais.

A singularidade, a partir de 2013, é a questão da revisão do plano de manejo que já começou a ser discutido no final do ano citado. Esse fato merece atenção futura e um apoio técnico para os representantes comunitários.

Quanto a visão da atual gestora, a principal vantagem de um conselho consultivo é que "facilita a tomada de decisões, tornando a administração mais democrática e cria mecanismos para melhorar a gestão".

Suas sugestões para melhorias do conselho foram "capacitação para conselheiros e melhora da infraestrutura para transporte/logística". Essa melhora vem de encontro com a dificuldade apontada dos conselheiros, com relação à distância de algumas comunidades para participarem das reuniões.

Notou-se, em geral, um esforço na direção do diálogo, do consenso, tanto da diretoria atual do parque como dos moradores.

\section{Considerações Finais}

O parque estadual da ilha do Cardoso é considerado um exemplo de gestão participativa diante da experiência de anos de participação ativa das comunidades no 
conselho gestor. Esse fato foi o que instigou a pesquisa ora apresentada, que teve como objetivo verificar a eficácia dos conselhos em unidades de conservação.

A pesquisa revelou que os conselhos são espaços primordiais de diálogo e esforço coletivo para a resolução de problemas. O sucesso participativo, não livre de contradições, remete ao respeito do Parque pelas comunidades envolvidas na questão sobre parques, além da busca por alternativas econômicas (turismo de base local, ecoturismo), apoio às pesquisas, apoio à gestão participativa, visando conciliar conservação, população e democracia. Isso é um mérito dos gestores desse parque desde o início da constituição desse conselho. Fato inovador, pois o mesmo foi instituído muito antes da obrigatoriedade do SNUC.

Além disso, sabe-se que em todas as esferas públicas, a participação popular é um desafio. Então, quais os motivos da participação popular nesse conselho?

Com base nas leituras realizadas e na realidade apresentada, pode-se dizer que o sucesso participativo no PEIC se deu (e se dá) impulsionado pela organização comunitária. Desde a constituição do território caiçara em parque, muitas transformações ocorreram, inclusive com ameaça ao direito de viverem nesses territórios. Essa luta, fez com que as pessoas se organizassem em torno dessa problemática. A efetiva participação, portanto, resulta do interesse, pois qualquer intervenção recai diretamente nas comunidades envolvidas. Isso faz com que, as lideranças sejam participativas, com organizações comunitárias bem desenvolvidas - isso faz total diferença. Esse fato foi constatado através dos entrevistados que disseram ter entrado para o conselho com o objetivo de inteirar-se dos assuntos e condições viáveis e melhores para os moradores.

Dessa forma, a pressão popular sobre a democracia representativa trouxe a eficácia nesse caso, tornando-a mais inclusiva. Sobre isso, Boaventura (2005, p.73) diz que:

[...] De maneira muito distinta, essas práticas buscam intensificar e aprofundar a democracia, quer reivindicando a legitimidade da democracia participativa, quer pressionando as instituições da democracia representativa no sentido de as tornar mais inclusivas, quer ainda, buscando formas de complementaridade mais densas entre a democracia participativa e a democracia representativa.

Analisando a legitimidade da participação, de acordo alguns indicadores de Loureiro (2008, p.249-250), quanto à capacidade de todos os envolvidos tomarem decisões; no caso do parque, isso acontece de forma consultiva e não deliberativa. $\mathrm{O}$ conselho deliberativo, nesse caso, seria ideal. Mesmo sabendo que os diretores, muitas vezes, respeitam o conselho, com muitos assuntos sendo deliberados prevalece ainda a centralização.

O tipo de linguagem pode ser um problema, ao se discutir a revisão do plano de manejo, sendo necessário um treinamento nesse sentido. Quanto à quantidade e representatividade das associações na gestão, o parque é um exemplo de paridade e há 
uma atuação coletiva e forte das populações. Contudo, reclamaram muito da distância, pois comunidades distantes não conseguem participar das reuniões.

Desse modo, os resultados apresentados expressaram que as pessoas veem os conselhos como caminhos importantes para o diálogo. Algumas críticas, aqui apresentadas, relacionam-se a fatores e circunstâncias que podem ser melhorados. Mas, isso não sana a essência da problemática, que é a questão da permanência.

A permanência na área é definida através dos critérios de tradicionalidade. O morador pode perder a tradicionalidade, caso ele se ausente por mais de três anos. Mas, isso se torna ambíguo, segundo Alvaides (2013, p.121, 122), pois esse "critério elaborado na revisão do plano de manejo se torna ambíguo quando nos confrontamos com a necessidade de sair da Ilha para concluir os estudos ou para tratamento de saúde".

Dessa forma, fica a questão - a gestão participativa é eficaz, mas se essas ações restritivas forem mantidas, a população, futuramente, poderá tornar-se um "museu vivo". Deseja-se que isso, de fato, não aconteça, e recomenda-se que, para os dias vindouros, haja uma mudança de categoria da área para reserva extrativista ou reserva de desenvolvimento sustentável, pois se acredita que a preservação cultural é tão importante quanto a conservação ambiental.

\section{Agradecimentos}

Minha gratidão à direção do Parque estadual da Ilha do Cardoso e aos representantes comunitários do conselho.

\section{Referências}

ADAMS, C. Caiçaras na mata atlântica: pesquisa científica versus planejamento e gestão ambiental. São Paulo: Annablume, 2000.

ALVAIDES, N. K. Tradições traduzidas: um estudo psicossocial sobre as memórias sociais dos moradores da comunidade do Marujá - Parque Estadual da Ilha do Cardoso. Dissertação (Mestrado em Psicologia) - Universidade Federal de São Carlos. São Carlos, 2013.

AMEND, S.; AMEND, T (Coord.). Espacios sin habitantes? Parques Nacionales de América del Sur. Caracas: Editorial Nueva Sociedad/IUCN, 1992.

BRASIL. Constituição (1988). Constituição da República Federativa do Brasil. Brasília, DF: Senado Federal: Centro Gráfico, 1988.

BRASIL. Lei $n^{\circ} 9985$, de 18 de Julho de 2000. Cria o Sistema Nacional de Unidades de Conservação - SNUC. Disponível em: http://www.mma.gov.br. Acesso em: 20 jul. 2000.

BRASIL. Decreto n. 4340, de 22 de Agosto de 2002. Regulamenta artigos da Lei no 9.985, de 18 de julho de 2000, que dispõe sobre o Sistema Nacional de Unidades de Conservação da Natureza - SNUC, e dá outras providências. Brasília, 2002. 
CAMPOLIM, M. B.; PARADA, I. L. S. ; YAMAOKA, J. G. Gestão participativa da visitação pública na comunidade do Marujá - Parque Estadual da Ilha do Cardoso. São Paulo: IF Sér. Reg. n. 33, p. 39-49, mai. 2008.

CASTORIADIS, C. As encruzilhadas do labirinto. São Paulo: Paz e Terra, 1986.

CLAY, J. Parks and people. Cultural Survival Quartely, Cambridge, v.9, n.1, p. 2-7, 1985.

CUNHA, M. C.; ALMEIDA, M.B. (Orgs.). Enciclopédia da Floresta. São Paulo: Cia das Letras, 2002.

DIEGUES, A.C. O mito moderno da natureza intocada. São Paulo: NUPAUB/USP, 1994.

FARIA, H. H. de. Eficácia de gestão de unidades de conservação gerenciadas pelo Instituto Florestal de São Paulo, 2004. Dissertação (Mestrado em Geografia) - Universidade Estadual Paulista. Faculdade de Ciências e Tecnologia. Presidente Prudente, 2004.

GADELHA, C. Proibido trabalhar: problema socioambiental dos filhos da Ilha do Cardoso. Dissertação (Mestrado em Antropologia Social) - Universidade de Campinas. Instituto de Filosofia e Ciências Humanas. Campinas, 2008.

GOMEZ-POMPA, A.; KAUS, A. Taming the wilderness mith. Reston: Bioscience, v.42, n.4, p. 271-279.

GUIZARDI, F. L.; PINHEIRO, R. Dilemas culturais, sociais e políticos da participação dos movimentos sociais dos Conselhos de saúde. Manguinhos: Ciência \& Saúde Coletiva, v. 11, n.3, p.797-805, 2006.

JUNQUEIRA, E. S.; FERREIRA, L. C. O caleidoscópio conservacionista: o SNUC como um acordo temporário no ambientalismo. São Domingos: Revista Vitas - Visões transdisciplinares sobre Ambiente e Sociedade, ano II, n.4, p.1-34, 2012.

LOUREIRO, C. F. B. Educação ambiental e gestão participativa na explicitação e resolução de conflitos. Revista Gestão em ação, Salvador, v.7 n.1, p.37-50, Jan./Abr. 2004.

LOUREIRO, C. F. B; CUNHA, C. C. Educação ambiental e gestão participativa de unidades de conservação: elementos para se pensar a sustentabilidade democrática. Ambiente \& Sociedade, Campinas, v. 11, n. 2, p.237-253, 2008.

MENDONÇA, A. L. F. A Ilha do Cardoso: o parque estadual e os moradores. 2000. 163 f. Dissertação (Mestrado em Ciências Florestais) - Universidade de São Paulo. Escola Superior de Agricultura "Luiz de Queiroz". Piracicaba, 2000.

MILANI, C. R. S. O princípio da participação social na gestão de políticas públicas locais: uma análise de experiências latino-americanas e européias. $R A P$, Rio de Janeiro, v.43, n. 3, p.551- 579, 2008.

POSEY, D. A. Consequências ecológicas da presença do índio Kayapó na Amazônia: recursos antropológicos e direitos de recursos tradicionais. In: CAVALCANTI, C.(Org.). 
Desenvolvimento e Natureza: estudos para uma sociedade sustentável. São Paulo: Cortez, p.177-194, 1995.

RISSO, L. C. Cultura caiçara: chave para a conservação ambiental: um estudo em Picinguaba - Ubatuba - SP. 1998. Trabalho de conclusão de curso (Geografia) Universidade estadual Paulista. Instituto de Geociências e Ciências Exatas. Rio Claro, 1998.

RISSO, L. C. Mapeamento das áreas suscetiveis a prática agroecológica no núcleo Picinguaba (Parque Estadual da Serra do Mar) - Ubatuba - SP, como subsídio a atividades sustentáveis. 2001. Dissertação (Mestrado em Manejo e conservação de recursos) - Universidade Estadual Paulista. Centro de Estudos Ambientais. Rio Claro, 2001.

RODRIGUES, C. L. Limites do consenso: territórios polissêmicos na mata atlântica e a gestão ambiental participativa. 2001. Tese (Doutorado em Geografia Humana) Universidade de São Paulo. Faculdade de Filosofia, Letras e Ciências Humanas. São Paulo, 2001.

SANTOS, B .de S.; AVRITZER, L. Para ampliar o cânone democrático. In: SANTOS, B.de S. (Org.). Democratizar a democracia: os caminhos da democracia participativa. 3.ed.Rio de Janeiro: Civilização brasileira, p.43-84, 2005.

SÃO PAULO (ESTADO). Secretaria do Meio ambiente, Instituto Florestal. Plano de gestão ambiental - fase 1 do Parque estadual da ilha do Cardoso. São Paulo, 1998.

STRECK, D. R.; ADAMS, T. Lugares da participação e formação da cidadania. Civitas, Porto Alegre, v.6, n.1, p .95-117, 2006.

TERBORGH; J.; PERES, C.A. O problema das pessoas nos parques. In: TERBORGH, J.; SCHAIK, C. V.; DAVENPORT, L.; RAO, M. (Orgs.). Tornando os parques eficientes: estratégias para a conservação da natureza nos trópicos. Curitiba: Editora UFPR, 2002.

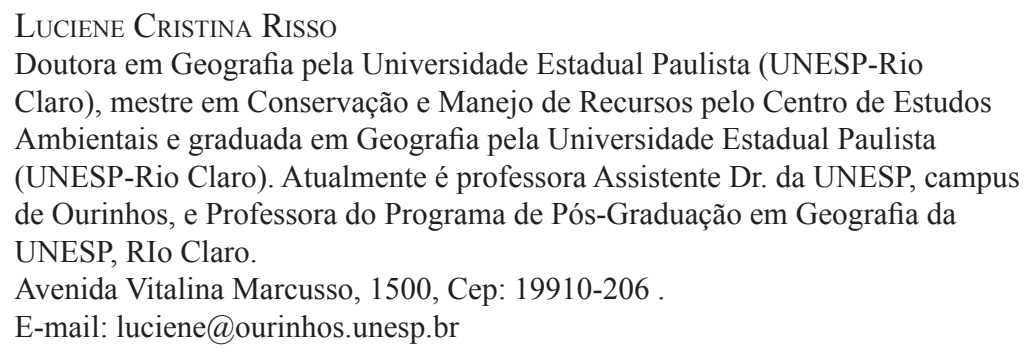

